\title{
A PRECARIZAÇÃO DO TRABALHO NO SUS NA PERSPECTIVA DA ENFERMAGEM HOSPITALAR*
}

Antônio César Ribeiro', Jackeline Félix de Souza², Juliana Lima da Silva²

'Enfermeiro. Doutor em Ciências. Universidade Federal de Mato Grosso. Cuiabá-MT-Brasil.

${ }^{2}$ Enfermeira. Universidade Federal de Mato Grosso. Cuiabá-MT-Brasil.

RESUMO: Estudo descritivo/transversal, construído a partir do conceito de trabalho precário no âmbito do Sistema Único de Saúde. Teve como objetivo identificar as condições laborais entre trabalhadores de enfermagem de um hospital público federal de ensino em Cuiabá - MT, analisando-as na perspectiva da gestão do trabalho. Os dados foram coletados no período de fevereiro a março de 2011 tendo como fonte as fichas funcionais mantidas pelo setor de pessoal do hospital. Os dados foram organizados e analisados conforme sua distribuição e frequência. Evidenciou-se a condição de trabalho precário e que esta tem crescido em detrimento das outras formas de vínculo. Assim, considerou-se que a gestão do trabalho da instituição caminha na contramão da política de desprecarização do trabalho no Sistema Único de Saúde, o que pode comprometer a qualidade do trabalho e vida dos profissionais de enfermagem.

DESCRITORES: Enfermagem; Mercado de trabalho; Sistema Único de Saúde.

\section{LACK OF EMPLOYMENT SECURITY IN THE SUS IN THE PERSPECTIVE OF HOSPITAL NURSING}

\begin{abstract}
This descriptive/transversal study is based on the concept of lack of job security in the ambit of the Unified Health System. It aimed to identify the working conditions among nursing staff in a public federal teaching hospital in Cuiabá, Brazil, analyzing these in the perspective of the management of the work. The data were collected in the period February-March 2011, using the employee data files maintained by the hospital's personnel department, the data were organized and analyzed according to distribution and frequency. The condition of insecure employment was evidenced, as was the fact that this has grown to the detriment of the other forms of employment link. Thus, it was considered that the management of the work in the institution is not in harmony with the policy of making employment more secure in the Unified Health System, which could compromise the quality of the nursing professionals' work and lives.
\end{abstract}

DESCRIPTORS: Nursing; Labor market; Unified Health System.

\section{LA PRECARIZACIÓN DEL TRABAJO EN SUS EN LA PERSPECTIVA DE LA ENFERMERÍA HOSPITALAR}

RESUMEN: Estudio descriptivo/transversal, construido con base en el concepto de trabajo precario en el ámbito del Sistema Único de Salud. Tuvo como objetivo identificar las condiciones laborales entre trabajadores de enfermería de un hospital público federal de enseñanza en Cuiabá - MT, analizándolas en la perspectiva de la gestión del trabajo. Los datos fueron obtenidos en el periodo de febrero a marzo de 2011, utilizándose como fuente las fichas funcionales mantenidas por el sector de personal del hospital. Fueron organizados y analizados de acuerdo con su distribución y frecuencia. Se evidenció la condición de trabajo precario y que esta viene creciendo en detrimento de otras formas de vínculo. Se consideró, por lo tanto, que la gestión del trabajo de la institución camina en la dirección contraria de la política de "desprecarización" del trabajo en el Sistema Único de Salud, lo que puede comprometer la cualidad del trabajo y la vida de los profesionales de enfermería.

DESCRIPTORES: Enfermería; Mercado de trabajo; Sistema Único de Salud.

*Artigo originado do trabalho de conclusão de curso de Graduação em Enfermagem. Universidade Federal do Mato Grosso, 2012.

Autor Correspondente:

Antônio César Ribeiro

Universidade Federal do Mato Grosso

Av. Tancredo Neves, 108 - 78065-230 Cuiabá-MT-Brasil.

E-mail: anceri@terra.com.br
Recebido: $14 / 08 / 2013$

Finalizado: 28/04/2014 


\section{INTRODUÇÃO}

Presente desde a emergência do trabalho assalariado, a precarização das relações de vínculo empregatício figura-se, no atual cenário mundial, como uma condição da contemporaneidade, que, alavancada pela sociedade capitalista, no contexto da globalização da economia e do neoliberalismo, ganha expressão crescente a partir da década dos anos de $1970^{(1-4)}$.

No Brasil, no âmbito do setor público, a condição de trabalho precário toma forma a partir da Emenda Constitucional $19^{(5)}$. Nominada emenda da reforma administrativa, esta tem como finalidade alterar dispositivos da Constituição Federal referentes à Administração Pública e às relações de trabalho do servidor público com o Estado. Entre as mudanças determinadas, destacam-se aquelas relativas ao regime jurídico único e a modificação das regras sobre a estabilidade no cargo público. A partir desse contexto permitir-se-ia a convivência de múltiplas formas de vínculos, que inclui desde o estatutário (regime jurídico único), passando pelo celetista, regido pela Consolidação das Leis do Trabalho, até os vínculos temporários (contrato por tempo determinado) e terceirizados ${ }^{(5-6)}$.

A partir daí, como condição emergente no âmbito das relações de trabalho no setor público, a precarização do trabalho é referida como o vínculo empregatício que se dá em condições incertas e imprevisíveis, nas quais seus riscos são assumidos principalmente pelo trabalhador e não pelo Estado, a quem compete, inclusive, regular e zelar pelas relações de trabalho, na perspectiva da proteção social|(1-4,7-8).

Observa-se na literatura imprecisão conceitual do termo trabalho precário, podendo variar como sendo: uma situação de déficit ou ausência de direitos de proteção social nas relações de trabalho; ou, decorrente de uma instabilidade do vínculo, do ponto de vista dos interesses dos trabalhadores; ou ainda, como associada às condições de trabalho em determinados setores da economia que geram vulnerabilidades aos trabalhadores quando inseridos no mundo do trabalho nessas condições. O que os diferentes conceitos ou entendimentos guardam em comum é a condição de vulnerabilidade, quer do ponto de vista da garantia do direito à proteção social, quer no sentido da segurança e da estabilidade no trabalho ${ }^{(1-4,7)}$.

Atualmente, o contexto político e econômico brasileiro, sobretudo no âmbito do Serviço Público, tem contribuído para que os gestores, na tentativa de reduzir gastos, optem pela redução de recursos humanos ou pela flexibilização das relações de trabalho, incluindo a terceirização, fatores que interferem na qualidade dos serviços prestados e na legitimidade dos interesses trabalhistas ${ }^{(1-2,4)}$.

Algumas instituições públicas mantêm seu quadro de pessoal com múltiplas formas de vínculos empregatícios e, consequentemente, diferentes remunerações entre os trabalhadores que possuem a mesma formação, condição que pode interferir diretamente no rendimento destes, trazendo o sentimento de desmotivação, o que compromete a qualidade dos serviços realizados. Nesta condição, o trabalhador não se vê motivado à elaboração de projetos inovadores em suas instituições e nem chegam a procurar cursos ou especializações para seu aprimoramento, tornando-se insatisfeitos e mal remunerados ou sem perspectiva de crescimento ${ }^{(4)}$.

No setor público brasileiro, especialmente o de saúde, a condição de trabalho precário assumiu tamanha dimensão que o Ministério da Saúde editou a política de desprecarização das relações de trabalho, instituindo as Mesas de Negociação Permanente e criando o Comitê Interinstitucional de Desprecarização do Trabalho no Sistema Único de Saúde (SUS) ${ }^{(7)}$.

No conjunto das formulações que sustentam a referida política, a condição de trabalho precário é definida por diferentes atores sociais, de acordo com as posições e lugares que estes ocupam no cenário da saúde pública brasileira. Assim, temse a posição assumida pelos representantes do Governo, por meio do Conselho Nacional de Secretários de Saúde e do Conselho Nacional de Secretários Municipais de Saúde, de que tal condição está

relacionada aos vínculos de trabalho no SUS que não garantem os direitos trabalhistas e previdenciários consagrados em lei, seja por meio de vínculo direto ou indireto. [defendendo que...] Mesmo que o vínculo seja indireto, é necessário garantir o processo seletivo e, sobretudo, uma relação democrática com os trabalhadores $^{(7: 13)}$. 
Já o segmento representante da classe trabalhadora defende a posição de que, além dos aspectos relacionados à proteção social, esta condição se define como sendo:

caracterizada não apenas como ausência de direitos trabalhistas e previdenciários consagrados em lei, mas também como ausência de concurso público ou processo seletivo público para cargo permanente ou emprego público no SUS ${ }^{(7: 13)}$.

O interesse em desenvolver este estudo está particularmente relacionado às condições de vínculo do trabalhador público no contexto do SUS, em Cuiabá, Estado de Mato Grosso-Brasil.

Assim, o presente estudo teve como objetivo identificar as condições laborais entre trabalhadores de enfermagem de um hospital público federal de ensino em Cuiabá-MT-Brasil, analisando-as na perspectiva da gestão do trabalho no SUS.

\section{MÉTODO}

O presente trabalho constitui-se um recorte cujo projeto matricial foi intitulado "estudo da composição da força de trabalho de enfermagem em Hospital Público Federal de Ensino, em Cuiabá - MT, na perspectiva da gestão do trabalho e da educação na saúde" financiado pela Fundação de Amparo á Pesquisa do Estado.

Trata-se de um estudo descritivo, com delineamento transversal e abordagem quantitativa, desenvolvido no período de setembro de 2010 a novembro de 2011.

O hospital estudado é mantido pelo Ministério da Educação/Universidade Federal de Mato Grosso e conveniado com o Sistema Único de Saúde. Implantado em 1984, tem atualmente capacidade para 118 leitos e presta os serviços de clínica médica, cirúrgica, pediatria, obstetrícia, unidades de terapia intensiva neonatal e adulta, além dos serviços ambulatoriais nas diferentes especialidades.

O serviço de enfermagem é organizado em uma diretoria, possui 281 trabalhadores nos diferentes níveis de formação, incluindo o atendente de enfermagem. Assim, a população estudada foi composta pelos trabalhadores de enfermagem (enfermeiros, técnicos, auxiliares e atendentes de enfermagem) que compõem o quadro de pessoal do serviço de enfermagem do hospital. Dada a natureza censitária do estudo foi considera $100 \%$ da população.

Foram excluídos do estudo apenas os trabalhadores de enfermagem cedidos para outros órgãos ou que não estivessem lotados eem exercício junto ao serviço de enfermagem do hospital.

Os dados foram coletados no período de fevereiro a março de 2011, e teve como fonte o cadastro de pessoal mantido pelo setor de pessoal do hospital, por meio de um instrumento fechado, contendo dados de identificação funcional, a saber: instituição contratante, natureza do vínculo, regime, jornada semanal, ano de ingresso, cargo/ perfil profissional, função que exerce e lotação, enquadramento funcional na carreira, outros vínculos.

Os dados foram organizados e armazenados com os recursos do programa estatístico EpiData 3.02. Concluída a digitação das informações e a constituição do banco de dados, estes foram estratificados a partir da variável natureza do vínculo, definidora da condição de trabalho precário ou não.

Posteriormente, foram analisadas as características que assumem as diferentes condições de trabalho, incluindo as comparações entre trabalhadores precarizados com aqueles outros que tiveram acesso ao cargo via concurso público.

Durante o estudo foram observadas e atendidas as definições éticas. Assim, o projeto matricial foi submetido à análise e parecer do comitê de ética em pesquisa com seres humanos do Hospital Universitário Júlio Müller, da Universidade Federal de Mato Grosso, sendo aprovado com o protocolo CEP/HUJM/UFMT n. 760/2010.

\section{RESULTADOS}

Do conjunto dos trabalhadores investigados, composto por 281 profissionais, a partir da variável "cargo ocupado", foi possível observar que a equipe de enfermagem do hospital é composta por $16,3 \%$ (46) de enfermeiros, $80,5 \%$ (226) de trabalhadores de enfermagem de nível médio-técnico e de 3,2\%, nove de nível elementar ou sem qualificação profissional específica (atendente de enfermagem). Dos trabalhadores de enfermagem de nível médio-técnico, 42,6\% 
(96) são auxiliares de enfermagem e 57,4\% (13) são técnicos de enfermagem. Da totalidade dos trabalhadores, a participação do sexo feminino mostrou-se majoritária, com 87,6\% (246) em relação ao sexo masculino, com 12,4\% (35). As faixas etárias com maior expressão encontradas foram àquelas situadas acima dos 40 anos, com $66,7 \%$ (188) entre estes, 18,8\% (53) estão acima dos 55 anos e próximos ao período aquisitivo para a aposentadoria. Relativo ao tempo de trabalho na instituição houve maior expressão aqueles trabalhadores que declararam de cinco a nove anos, com 44,1\% (124), seguidos por aqueles que declararam mais de 25 anos, 19,9\% (56). Observou-se ainda, um número considerável daqueles que declararam tempo de serviço menor que cinco anos, 29,1\% (65).

Sobre a jornada semanal de trabalho e sua distribuição em turnos, observa-se uma diversidade nas formas de revezamento, inclusive para o mesmo cargo e turno de trabalho. Somente para o turno do dia foram identificadas jornadas diárias de trabalho em período integral, sendo oito horas de segunda a sexta-feira $1 \%$, três combinadas com jornadas de $12 \times 36$ horas, com 4,9\% (14); $12 \times 60$, com 14,9\% (42); e de seis horas, distribuídos pela manhã, com 19,6\% (55) ou tarde, com 19,3\% (54). Já para o turno da noite foram identificadas as jornadas de $12 \times 60$, com 29,9\% (84) e de 12 x 36, com 10,4\% (29).

Observou-se a predominância de trabalhadores que possuem vínculo formal com a instituição, representados pelos estáveis, por tempo de serviço, e efetivos, que tiveram acesso ao cargo pela via do concurso público, com 74,1\% (208). Porém, identificou-se ainda a coexistência de trabalhadores de enfermagem submetidos à condição de trabalho precário, com 25,9\% (73). Neste mesmo diapasão, observou-se que $100 \%$ dos trabalhadores que estão submetidos ao contrato temporário não possuem vínculo direto com a instituição mantenedora do hospital, mas sim, com a Secretaria Municipal de Saúde de Cuiabá (SMS/CBA).

Há também, com menor expressão, a presença de trabalhadores de enfermagem cedidos pela Secretaria de Estado de Saúde de Mato Grosso (SES/MT), 2,4\%, sete, porém, todos mantendo vínculo efetivo com a instituição empregadora.

O Quadro 1 detalha as características relativas à natureza dos vínculos em relação à instituição empregadora, reafirmando a condição de estáveis ou efetivos, via concurso público, daqueles trabalhadores de enfermagem vinculados diretamente ao Ministério de Educação (MEC) e dos prestadores de serviços, com vínculo empregatício com a SMS/CBA, além daqueles que são efetivos no Serviço Público Estadual e cedidos para o hospital. Entre os trabalhadores precarizados, nenhum mantém vínculo com o MEC.

Numa análise mais cuidadosa dos dados sobre a distribuição temporal da natureza do vínculo dos sujeitos, de 1984 a 2011, mostra o comportamento da forma de acesso ao emprego público em relação ao tempo, evidenciando que desde a implantação do hospital em 1984, a natureza dos vínculos têm se modificado e que, a partir do ano 2000, houve incremento da precarização do trabalho em detrimento das outras formas de contratação e de recrutamento e seleção de pessoal via concurso público.

Quadro 1 - Distribuição dos sujeitos conforme Instituição Empregadora e Natureza do vínculo. Cuiabá-MT-Brasil, 2011

\begin{tabular}{|l|c|c|c|}
\hline Instituição Empregadora & Estável & Efetivo (concurso) & Contrato Temporário \\
\hline Ministério da Educação & 62 & 135 & 0 \\
\hline SecretariaEstadualdeSaúde & 0 & 7 & 0 \\
\hline SecretariaMunicipaldeSaúde & 0 & 0 & 73 \\
\hline Outros & 1 & 3 & 0 \\
\hline Total & 63 & 145 & 73 \\
\hline
\end{tabular}




\section{DISCUSSÃO}

Os dados revelaram a distribuição dos trabalhadores de enfermagem conforme a natureza do vínculo, instituição empregadora e jornada semanal de trabalho. A combinação destas três variáveis permitiu responder a questão central do estudo, relativo às condições de trabalho do ponto de vista do vínculo.

O processo de flexibilização do trabalho no âmbito do setor público brasileiro se acentuou a partir da Emenda Constitucional 19/1998, contudo, cabe considerar que em 2007 o Supremo Tribunal Federal suspendeu, por meio de medida cautelar, as modificações do caput do artigo 39 da Constituição, sofridas pela referida emenda, restabelecendo o regime jurídico único para os servidores públicos da administração pública direta(5-6).

Considerando que trabalhadores estáveis são aqueles que ingressaram no serviço público cinco anos antes da homologação da Constituição Federal de 1988 e os efetivos são aqueles que obtiveram acesso ao cargo público por meio de concurso público, ou seja, todos submetidos ao Regime Jurídico Único, dessa forma, fica evidenciada a inconstitucionalidade presente na gestão do trabalho no hospital ${ }^{(9)}$.

Outra característica que chama a atenção a partir dos dados apresentados, reafirmando o acima exposto, está na variável jornada de trabalho, sendo possível identificar que 100\% dos trabalhadores precarizados assumem carga horária semanal maior que daqueles estáveis ou efetivos. A coexistência de diferentes jornadas de trabalho e suas formas de distribuição, foi observada em outro estudo, desenvolvido no mesmo hospital, inclusive para um mesmo turno e setor de trabalho(10), estando tal distribuição a depender da natureza do vínculo - estatutário ou serviços prestados. Neste sentido, foram identificados trabalhadores ocupantes do mesmo cargo e atuantes num mesmo setor, porém praticando jornadas de trabalho diferenciadas, a depender da natureza do vínculo.

Segundo encontrado na literatura que trata das questões dos recursos humanos no $\operatorname{SUS} S^{(4,7)}$, algumas instituições públicas possuem um quadro de profissionais com diferentes vínculos empregatícios e, consequentemente, distintas remunerações entre os profissionais que possuem a mesma formação e função. Neste estudo podese observar que se soma a estas características, como típicas do trabalho precário, a diferenciação de jornada de trabalho a que estão obrigados os submetidos a esta condição, podendo-se inferir, a partir daí, que a permanência no emprego está na dependência da subordinação do trabalhador às condições locais de trabalho.

Nas mais diversas áreas de trabalho do setor público e, em especial, na área da saúde, a existência do trabalho precário afeta e traz grandes consequências, não só aos trabalhadores, que, por receio de ficarem sem emprego, acabam se sujeitando à condição de ausência de proteção social, mas também às suas famílias e à própria instituição, pois esses trabalhadores submetem-se à longas jornadas de trabalho e, no geral, tem suas remunerações inferiores àquelas praticadas para os servidores públicos de carreira, necessitando ter mais de um vínculo empregatício e, na maioria das vezes, não recebem ou não participam de educação continuada ou algum tipo de capacitação profissional ${ }^{(4,7)}$.

Segundo levantamento apresentado pelo Jornal Online Diário de Cuiabá (2011), no Estado de Mato Grosso a formação superior em enfermagem, que era ofertada apenas por uma Instituição de Ensino Superior, com sede na Capital, no início da década dos anos de 1990 passa, no final dos anos 2000, a ser ofertada por 17 faculdades, entre públicas e privadas, distribuídas em todo o Estado de Mato Grosso, sendo seis apenas na Grande Cuiabá(11).

O mesmo ocorreu com a formação em nível médio em enfermagem, a partir da edição da última Lei de Diretrizes e Bases da Educação Nacional ${ }^{(12)}$, que promoveu a reformulação e a ampliação da Educação Profissional de Nível Técnico no Brasil. Tais mudanças resultaram na extinção dos cursos de qualificação para auxiliares de enfermagem ao tempo em que ampliou a oferta de vagas para a formação em nível técnico.

Neste contexto, a ampliação da oferta de vagas para a profissionalização na área de enfermagem, sem que os serviços ampliassem a oferta de postos de trabalho na mesma proporção, tem gerado o que pode ser caracterizado como o desemprego estrutural para esta categoria, já que a disponibilidade de mão-de-obra vai muito além da capacidade de absorção pelo 
mercado de trabalho ${ }^{(1-2,4)}$. Consequentemente, a disponibilidade de oferta de mão-de-obra tem facilitado à ampliação do trabalho precário, visto que o trabalhador acaba submetendo às piores condições laborais como forma de garantir sua permanência no emprego e renda.

Diante das evidências constatadas na condição de trabalho precário entre trabalhadores de enfermagem no hospital estudado, ainda que restrita ao um quarto dos seus profissionais, o crescimento desta condição coloca em questão a forma de gestão do trabalho naquele espaço, considerando dois aspectos fundamentais. $\mathrm{O}$ primeiro relaciona-se diretamente ao próprio trabalhador e ao seu modo de afazeres, a partir da perspectiva colocada pela política nacional de desprecarização do trabalho no SUS, cuja agenda assume o sentido de resgate da condição de trabalhador precarizado, promovendo a sua reinserção no mundo do trabalho pela via da constitucionalidade, garantindo assim os seus direitos trabalhistas e de cidadania ${ }^{(7)}$. O segundo relaciona-se diretamente com a gestão do trabalho em enfermagem e objetivos do hospital estudado e os efeitos deletérios da manutenção do trabalhador precarizado, em especial quando considerada a satisfação no trabalho como condição para um processo de produção de acordo com a missão institucional.

Considerando tal tendência, combinada com a concentração das faixas etárias e tempo de serviço próximas do período aquisitivo de aposentadoria, e o fato do sexo feminino ser majoritário, tendo menor tempo de serviço para aposentar, caso a instituição não reveja sua prática de gestão do trabalho, a curto ou médio prazo, haverá predominância de trabalhadores submetidos à condição de trabalho precário, o que vai à direção oposta da Política Nacional de Desprecarização do Trabalho no SUS ${ }^{(7)}$.

Neste sentido, considerando o papel do enfermeiro no que diz respeito à gestão da força de trabalho como parte integrante do processo de trabalho administrar em enfermagem ${ }^{(13)}$, a precarização dos vínculos coloca-se como um grande desafio, já que os anseios, as expectativas e a satisfação do trabalhador estão entre os elementos fundamentais para a produção de uma assistência de qualidade ${ }^{(14)}$.

Outro aspecto que merece ser retomado a partir dos achados relaciona-se as características que o trabalho precário assume na realidade estudada, o que supera a mera ausência de proteção social e ingresso sem concurso público ${ }^{(7)}$. A evidência de que a condição do trabalhador submetido ao contrato temporário implica em sobrecarga da jornada de trabalho e a própria vinculação indireta com a instituição onde trabalha, explicita o sentido de constrangimento e de hiposuficiência a que este conjunto de trabalhadores encontrase submetido. Considerando particularmente os aspectos relativos à diferenciação da jornada de trabalho de um mesmo grupo profissional, justificada apenas pela natureza do vínculo, evidencia-se uma política discriminatória e excludente, que se efetiva na contramão a luta histórica da categoria de enfermagem pela regulamentação da sua jornada de trabalho ${ }^{(15)}$.

Frente a tal realidade pode-se considerar que este conjunto de condições amplia e expande o conceito de trabalho precário, a partir da conceituação corrente no âmbito do SUS ${ }^{(1,3-4,7)}$.

\section{CONSIDERAÇÕES FINAIS}

O estudo evidenciou a coexistência de múltiplas formas de contrato e vínculo entre os trabalhadores de enfermagem, incluindo aqueles precarizados. Este também constatou que a precarização do trabalho tem se expressado como uma tendência desde a implantação do hospital, acompanhando a emergência e o crescimento desta condição no contexto mais geral do setor público, em especial o de saúde.

Neste contexto, o estudo identificou condições que são impostas aos trabalhadores contratados que sugerem a ampliação do conceito de trabalho precário, considerando que, uma vez nesta condição, estes estão obrigados a uma jornada de trabalho ampliada.

Frente ao evidenciado, no que se refere à forma de estar no trabalho e os efeitos deletérios sobre a vida e a capacidade produtiva do trabalhador de enfermagem; considerando a centralidade que este assume no contexto da assistência hospitalar, coloca-se aqui a questão do desafio imposto à gestão do trabalho, como parte integrante do processo de trabalho administrar em enfermagem, atividade privativa do enfermeiro.

Neste contexto, evoca-se o sentido do processo de trabalho participar politicamente 
para o gestor/administrador de enfermagem, como forma de buscar garantir condições de trabalho que favoreçam a satisfação e o entusiasmo do trabalhador, na perspectiva da produção de uma assistência de qualidade dentro de um ambiente de trabalho humanizado.

Considera-se ainda que as características encontradas não sejam restritas ao hospital estudado, mas, se assemelham ao contexto nacional do trabalho em saúde, no âmbito do serviço público. Neste sentido, tomando a política de Recursos Humanos proposta como um dos eixos estruturante do SUS, a gestão do trabalho deve buscar a valorização do trabalho e do trabalhador; o tratamento dos conflitos de interesse; a humanização das relações de trabalho, devendo se converter numa agenda de gestão no sentido de reverter às condições de trabalho que comprometem tanto a qualidade dos serviços produzidos quanto a qualidade de vida do trabalhador.

\section{REFERÊNCIAS}

1. Kalleberg AL. Crescimento do trabalho precário: um desafio global. Rev. bras. cienc. soc. 2009; 24(69):2130 .

2. Alves G. Dimensões da reestruturação produtiva: ensaios de sociologia do trabalho. $2^{\mathrm{a}}$ Ed. Londrina: Praxis; 2007.

3. Amorim LKA, Carvalho CA, Souza NVDO, Cruz ESER, Silva MGV. O trabalhador sem vínculo previdenciário e a vivência cirúrgica: uma contribuição da enfermagem. Cienc. Cuid. Saúde. [Internet] 2012;11(2) [acesso em 15 de jul 2013]. Dispónível: http://periodicos.uem.br/ ojs/index.php/CiencCuidSaude/article/view/14931/pdf.

4. Nogueira RP, Baraldi S, Rodrigues VA. Limites críticos da noção de precariedade e desprecarização do trabalho na administração pública. In: Barros AFR, Santana JP, Santos Neto PM, organizadores. Observatório de recursos humanos em saúde no Brasil. Brasília (DF): Ministério da Saúde; 2004. v.2 p. 81-103.

5. Congresso Nacional (Brasil). Emenda Constitucional n. 19 de 4 de junho de 1998. Modifica o regime e dispõe sobre princípios e normas da Administração Pública, servidores e agentes políticos, controle de despesas e finanças públicas e custeio de atividades a cargo do Distrito Federal e dá outras providências. Diário Oficial da República Federativa do Brasil, Brasília, Congresso Nacional; 1998.

6. Silva MM. A reforma administrativa e a Emenda
Constitucional 19/1998. Gestão Pública on line [Internet]. 2005 [acesso em 15 nov 2011]. Disponível: http://www.direitopositivo.com.br/modules. php? name $=$ Artigos\&file $=$ display $\&$ jid $=168$

7. Ministério da Saúde (BR). Secretaria de Gestão do Trabalho e da Educação na Saúde. Departamento de Gestão e da Regulação do Trabalho em Saúde. Programa Nacional de Desprecarização do Trabalho no SUS: DesprecarizaSUS: perguntas \& respostas: Comitê Nacional Interinstitucional de Desprecarização do Trabalho no SUS Brasília; 2006.

8. Freitas GF, Fugulin FMT, Fernandes MFP. A regulação das relações de trabalho e o gerenciamento de recursos humanos em enfermagem. Rev Esc Enferm USP. 2006;40(3):434-8.

9. Brasil. Constituição da República Federativa do Brasil. Brasília: Senado; 1988.

10. Ribeiro AC, Mattos CMM. Dimensionamento de pessoal de enfermagem em uti-neonatal de hospital público federal de ensino. Cogitare enferm. 2011;16(3):455-62.

11. Anjos A. Enfermagem: manifestantes percorrem sete hospitais. 2011 [Internet] [acesso em 15 nov 2011]. Disponível: http://www.diariodecuiaba.com.br/ detalhe.php?cod=398045

12. Brasil. Lei n. 9.394/1996, de 20 de dezembro de 1996. Estabelece as diretrizes e bases da educação nacional. Diário Oficial da República Federativa do Brasil, Brasília, 23 dez. 1996. Seção1:1.

13. Tronchin DMR, Melleiro MM, Takahashi RT. A qualidade e a avaliação dos serviços de saúde e de enfermagem. In: Gerenciamento em enfermagem. Kurcgant P. (organizadora). Rio de Janeiro: Guanabara Koogan; 2005. p. 75-87.

14. Sanna MC. Os processos de trabalho em enfermagem. Rev. bras. enferm. [Internet] 2007;60(2) [acesso em 22 jul 2013]. Disponível: http://dx.doi.org/10.1590/S003471672007000200018

15. Pires DEP, Lopes MGD, Silva MCN, Lorenzetti J, Peruzzo SA, Bresciani HR. Jornada de 30 horas semanais: condição necessária para assistência de enfermagem segura e de qualidade. Enferm. Foco. 2010;1(3):114-8. 